the male and the female clustered closely together. Similar patterns were observed with sequential samples from single individuals, but not with unrelated samples.

DNA sequencing was also used in the 'Florida dentist' case ${ }^{4}$, but the results were not used as evidence because the case was settled out of court. Still, it is interesting to compare the strategies used in these two investigations. One important difference is that we studied the pol gene instead of the more variable env gene. Because a relatively stable region was analysed, a rapid direct sequencing method could be used which eliminates the need to analyse multiple clones from each sample.

Based on the genetic analysis and other evidence in the case, the verdict from the district court was upheld in the court of appeal. Furthermore, the defen-

\section{Therapsids and transformation series}

SIR - In his discussion of the supposed Palaeocene therapsid fossil Chronoperates, $\mathrm{Gee}^{1}$ presents a distorted picture of current phylogenetic practice among vertebrate systematists. He says that the "distinction between mammals and therapsids" is a side-effect of rearranging a bush of convergent mammal-like lineages, post hoc, into an ordered stem lineage. He also asserts that Chronoperates "is a fossil out of time only if one assumes that the transformation series between mammals and reptiles happened in the way the textbooks would have us believe".

This assertion is mistaken. There exists a clade Mammalia, characterized by the possession of certain derived features, whose earliest known representatives date from the Upper Triassic; Chronoperates (if correctly interpreted by Fox et $a .^{2}$ ) lacks some of these derived characters and thus presumably represents a sister-group of the Mammalia; the last common ancestor of the mammals and Chronoperates must antedate the earliest known mammals, and is thus of Upper Triassic or earlier date; the occurrence of Chronoperates in the Palaeocene therefore implies the existence of an otherwise undocumented lineage extending through the Jurassic and Cretaceous. It is indeed a "fossil out of time".

The question of the "distinction between mammals and therapsids" is essentially a semantic rather than a phylogenetic problem, and has no real bearing on the phylogenetic or temporal position of Chronoperates. Gee accepts that the numerous derived mammalian characters are unlikely to have arisen simultaneously, and recognizes that this implies the existence of a stem lineage dant was not given leave to appeal to the supreme court. This study demonstrates the power of direct genomic sequencing in forensic medicine, but the method also has broad applications outside this field.

\section{J. Albert}

Department of Virology,

National Bacteriological Laboratory,

\section{J. Wahlberg}

\section{Uhlén}

Department of Biochemistry and Biotechnology,

Royal Institute of Technology, S-100 44 Stockholm,

\section{Sweden}

1. Hultman, T., Ståhl, S., Hornes, E. \& Unlén, M. Nucleic. Acids Res. 17, $4937-4946$ (1989).

2. Wahlberg, J., Lundeberg, J., Hultman, T. \& Uhlén, M Proc. natn. Acad. Sci. U.S.A. 87, 6569-6573 (1990).

3. Wahiberg, J. et al. FASEB J. 6, 2843-2847 (1992). 4. Ou, C.-Y. et al. Science 256, 1165-1171 (1992).

lineages carrying sequentially arranged sister taxa (plesions) below the crown group $^{7}$, whereas other groups seem to show a more symmetrical arrangement ${ }^{8}$. The patterns do not appear to be affected by the removal of recent taxa ${ }^{6}$, and the search for alternative topologies has not been strikingly successful ${ }^{4,5}$. These are all interesting results, worthy of further study; Gee does them no service by conflating them with 'join-thedots' transformation series.

Per Erik Ahlberg

Department of Zoology and University Museum,

University of Oxford,

South Parks Road,

Oxford OX1 3PS, UK

1. Gee, H. E. Nature 360, 529 (1992)

2. Fox, R. C., Youzwyshyn, G. P. \& Krause, D. W. Nature 358, 233-235 (1992).

3. Panchen, A. L. Zool. J. Linn. Soc. 74, 305-328 (1982).

4. Panchen, A. L. \& Smithson, T. R. in The Phylogeny and Classification of Tetrapods (ed. Benton, M. J.) 1-32 (Clarendon, Oxford, 1988).

5. Godfrey, S. J. Phil. Trans. R. Soc. 8323, 75-133 (1989).

6. Gauthier, J., Kluge, A. G. \& Rowe, T. Cladistics 4 105-209 (1988)

showing a sequence of character acquisition. However, he seems to believe that the very existence of the crown group will prejudice the investigation, giving undue importance to those characters which would determine the position of the taxon on the stem. This idea has been pursued by Panchen ${ }^{3}$, who has explicitly tried to look for more 'symmetrical' alternatives to these orderly sequences of sister taxa. But the resultant cladograms ${ }^{4}$ are generally less parsimonious than their competitors ${ }^{5}$; it seems that the orderly appearance of derived characters is not an artefact.

Gee goes on to conflate this criticism with the unrelated and discredited practice of arranging fossil taxa in "ancestordescendant" sequences. People who study the mammalian stem lineage have used cladistic techniques for more than a decade, and their phylogenetic hypotheses are falsifiable within that methodology. They are emphatically not looking for ancestors.

Gee has missed the point of the paper by Gauthier et al. ${ }^{6}$. It is not the mammals, but the 'therapsids' near the middle of the stem group which cause the flip from one tree topology to another. Removing the recent groups does not affect the outcome. The stem taxa change the topology because they demonstrate, through the combination of characters they possess, that the supposed mammalian-bird synapomorphies are in fact convergent. The methodology of Gauthier et al. is not unsound because it fails to give primacy to data from recent groups; rather, it demonstrates the untenability of this 'transformed cladistic' precept.

Cladistic analyses of several major vertebrate groups have revealed stem
7. Patterson, C. \& Rosen, D. E. Bull. Am. Mus. Nat. Hist. 158, 81-172 (1977).

8. Ahlberg, P. E. Zool. J. Linn. Soc. 103, 241-287 (1991).

SIR - The announcement of an anachronistic fossil - the mammal-like reptile Chronoperates ${ }^{1}$ — and the ensuing arguments over its true identity ${ }^{2-4}$ do indeed open up old debates as Gee points out in News and Views ${ }^{5}$. The debates concern the difficulty of interpreting incomplete fossils, the nature of groups, and how we recognize their members.

As Rowe and Gauthier acknowledge ${ }^{6}$, no one has had difficulty in recognizing a Recent mammal (although there was a 'near miss' when the platypus was first brought back to Europe). Mammalian characters are obvious, and mammals can be diagnosed (distinguished) from their Recent sister-group (birds or birds+crocodiles). They are clearly monophyletic, with a single history which is separate from that of any other Recent group. Part of that history will be evidenced by animals now extinct and which, individually, possessed some, but not all, of the characters of modern mammals. These extinct animals are nevertheless mammals (see ref. 7) and can be arranged sequentially along an inferred stem lineage leading from the origin of mammals to the cladogenetic event which led to modern mammals (crown-group mammals). The fossils which may be arranged along this lineage are the traditional 'mammal-like reptiles'. Recent attempts to divide up this lineage arbitrarily into mammals and non-mammals on some 'key character' (see refs 6,8 ) are subjective. Chronoperates is clearly a mammal as it shares a synapomorphy of mammals (a mas- 